UCRL-ID-123900

\title{
A Real-Time Earthquake Alert System for the Greater San Francisco Bay Area: A Prototype Design to Address Operational Issues
}

\author{
P. E. Harben \\ S. Jarpe \\ S. Hunter
}

May 28, 1996

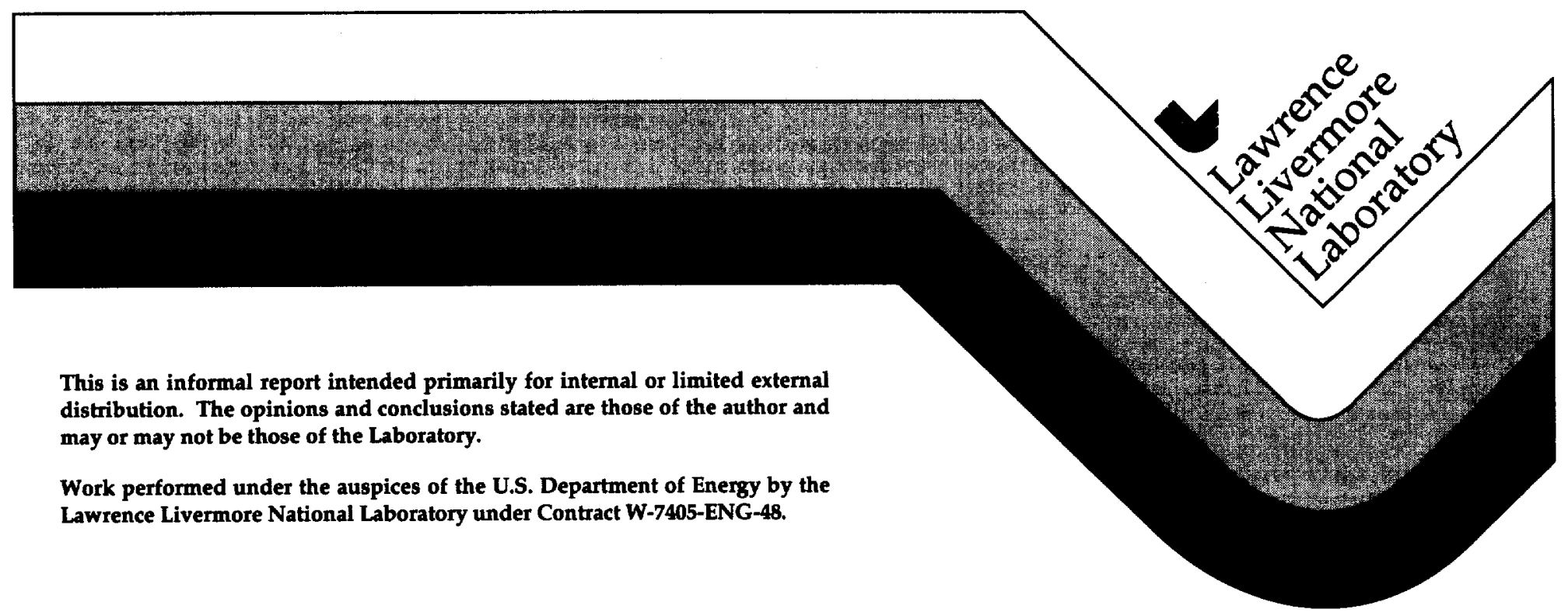




\section{DISCLAIMER}

This document was prepared as an account of work sponsored by an agency of the United States Government. Neither the United States Government nor the University of California nor any of their employees, makes any warranty, express or implied, or assumes any legal liability or responsibility for the accuracy, completeness, or usefulness of any information, apparatus, product, or process disclosed, or represents that its use would not infringe privately owned rights. Reference herein to any specific commercial product, process, or service by trade name, trademark, manufacturer, or otherwise, does not necessarily constitute or imply its endorsement, recommendation, or favoring by the United States Government or the University of California. The views and opinions of authors expressed herein do not necessarily state or reflect those of the United States Government or the University of California, and shall not be used for advertising or product endorsement purposes.

This report has been reproduced directly from the best available copy.

Available to DOE and DOE contractors from the Office of Scientific and Technical Information

P.O. Box 62, Oak Ridge, TN 37831

Prices available from (615) 576-8401, FTS 626-8401

Available to the public from the National Technical Information Service

U.S. Department of Commerce

5285 Port Royal Rd.,

Springfield, VA 22161 


\title{
A Real-Time Earthquake Alert System for the Greater San Francisco Bay Area: \\ A Prototype Design to Address Operational Issues
}

\author{
P. E. Harben \\ S. Jarpe \\ S. Hunter
}

May 28, 1996 



\title{
A Real-Time Earthquake Alert System for the Greater San Francisco Bay Area: A Prototype Design To Address Operational Issues
}

\author{
P. E. Harben, S. Jarpe, and S. Hunter
}

\section{Introduction}

On November 3, 1868, the San Francisco Daily Evening Bulletin ran an editorial promoting the development of a real-time earthquake warning system [1].

A very simple mechanical contrivance can be arranged at various points from 10 to 100 miles from San Francisco, by which a wave of the earth high enough to do damage will start an electric current over the wires now radiating from this city and almost instantaneously ring an alarm bell, which should be hung in a high tower near the center of the city.

The idea is not new. The modern concept of a real-time earthquake warning system was introduced in 1985 [2]. The proposed system consisted of a distributed network of real-time strong-motion monitoring stations that telemetered data in real-time to a central analysis facility. The central facility could transmit earthquake parameter information (e.g., magnitude, location) to an area before elastic wave energy arrived.

In 1989, a report commissioned by the State of California was released [3] on the technical and economic feasibility of a real-time earthquake warning system for the state. The study attempted a cost-benefit analysis for implementing and operating a dedicated earthquake warning system. Installation of a dedicated system for the Los Angeles Basin was estimated at \$3.3-5.8 million with an annual operating cost of \$1.6-2.4 million. Questionnaires were sent to public and private institutions to determine the value of a system that could provide seconds of warning before an earthquake. The study admitted that "an assessment of the value of an EWS [Earthquake Warning System] is inherently difficult because potential users are asked to identify uses for a nonexistent system." The study then concluded: "It would not be justified, on a cost-benefit basis, to construct an EWS at this time."

In 1991, the National Academy of Sciences (NAS) issued a report entitled Real-Time Earthquake Monitoring [4], which drew heavily on the State of California study. However, the NAS study concluded that a survey to determine the utility of a system that has never existed "is not reliable," and it cited examples of new technologies that were initially turned down by potential users, such as telephones which were rejected the British Post Office in 1876 in favor of messenger boys. The NAS strongly urged that prototype realtime warning systems be developed for use in earthquake-prone areas. 
Although the concept of a real-time earthquake monitoring and warning system has been around for a long time and it has been technically feasible to implement such a system, there is no history of an operational system in the United States. Issues such as false alarms and accuracy of the real-time earthquake parameter estimates cannot be fully anticipated from a theoretical or computer study. An actual operational prototype will help scientists determine which areas require further research and development.

In this paper, we describe a prototype for a real-time earthquake alert system (EAS) in the San Francisco Bay Area. Our approach is pragmatic, attempting to establish a prototype system at a low cost and quickly. As operational experience with a functioning prototype system is gained, the most important system enhancements will become apparent.

Considering the modest cost (about $\$ 500,000$ ) in developing a prototype real-time warning system in the greater San Francisco Bay Area and the high potential for substantial earthquake mitigation, it is surprising that such a system has not been developed. Systems in the Bay Area such as the University of California at Berkeley Rapid Earthquake Data Integration (REDI) system [5] are important developments in rapid notification, giving accurate estimates of earthquake parameters in the immediate earthquake aftermath. These systems do not provide real-time warning capability and are not on a development path that will produce a real-time system in the near future since the data transmission, analysis, and information broadcast system all have time delays that preclude true realtime operation.

We stress that real-time earthquake warning is becoming an important new frontier of earthquake mitigation research and development. A real-time warning system has the potential to make major contributions in protecting the public and mitigating earthquake damage.

\section{System Concept Overview}

The purpose of the EAS is to "outrun" the seismic energy released in a large earthquake with radio waves and rapid processing via the central processing unit (CPU), to warn a region before strong motion will occur (Figure 1). The warning times involved are short, from 0 to 30 second or so; consequently, most responses must be automated. Four distinct subsystems make up the EAS:

1. A distributed strong-motion seismic network.

2. A central processing station.

3. A warning communications system.

4. User receiver and response systems.

The only way to detect an earthquake soon after it ruptures is to have a sensor near the rupture epicenter, and the only way to know the earthquake is large is to have that 


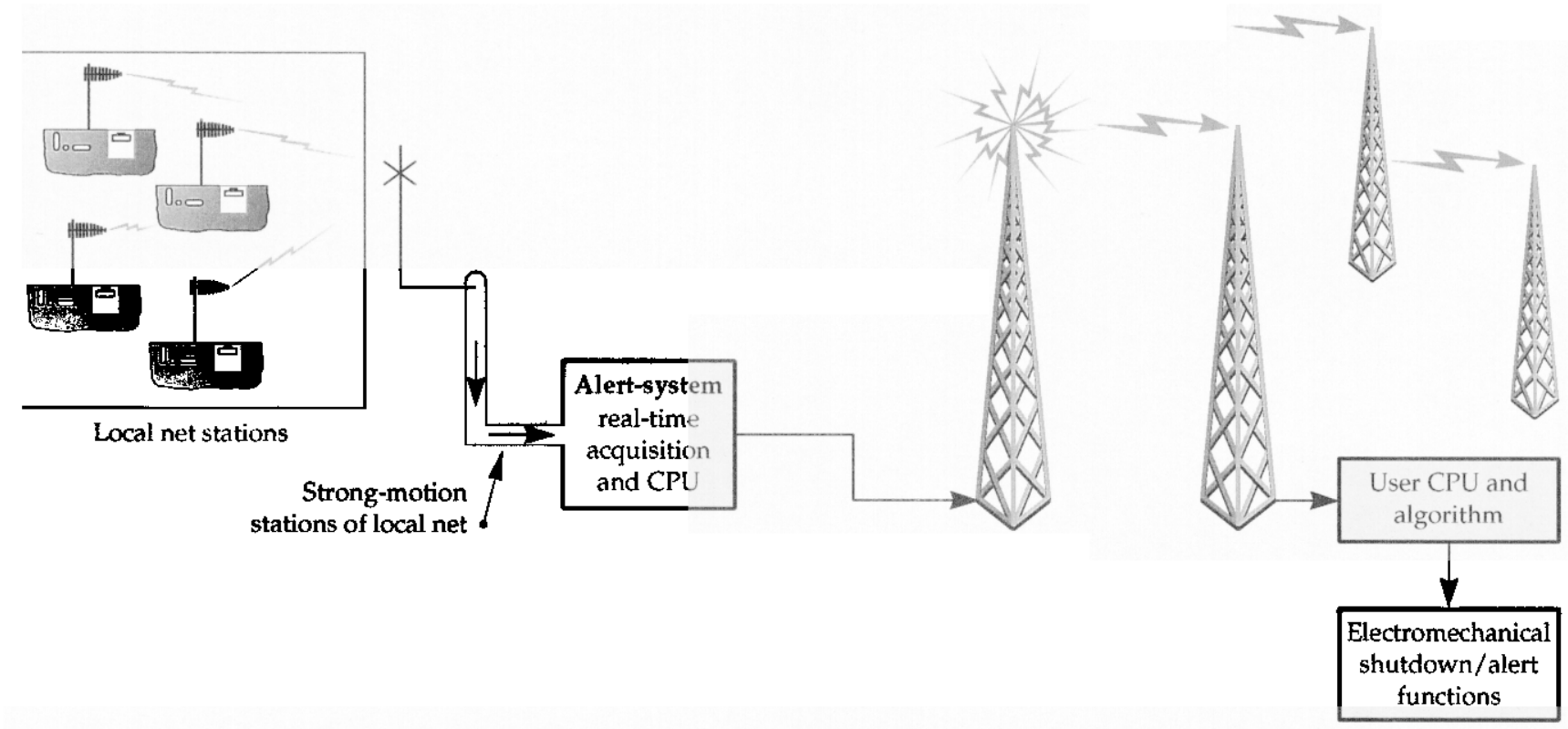

Figure 1. The earthquake alert system concept.

sensor stay on-scale during large ground motions, i.e., to be a strong-motion sensor. We cannot predict where the epicenter of the next large earthquake to affect the Bay Area will be. Therefore, we must distribute strong-motion sensors along all the major faults such that for any anticipated earthquake, sensors will be nearby. This distribution of strongmotion sensors constitutes the strong-motion network.

The strong-motion network telemeters data in real time to a central receiving center. The central receiver is connected to a powerful CPU that can perform real-time calculations on the incoming data streams to obtain estimates of the earthquake location and size, the time from initial rupture, and the reliability of the estimate. These estimates are updated as more data arrive from the strong-motion network. This central receiver and analysis center constitute the central processing station.

The earthquake parameter estimates calculated by the central CPU are transmitted via a dedicated pager system as a digital information packet that can be received throughout the greater Bay Area. New digital information packets are transmitted when the CPU calculates new parameter estimates as more data arrive from the strong-motion network. The dedicated paging system constitutes the warning communication system.

The digital information packets are received by a paging receiver and acted on according to the user's needs (Figure 2). The continually updated stream of digital information packets will allow users to develop their own automated decision-analysis responses based on a trade-off between the earthquake parameter estimates and each user's toler- 


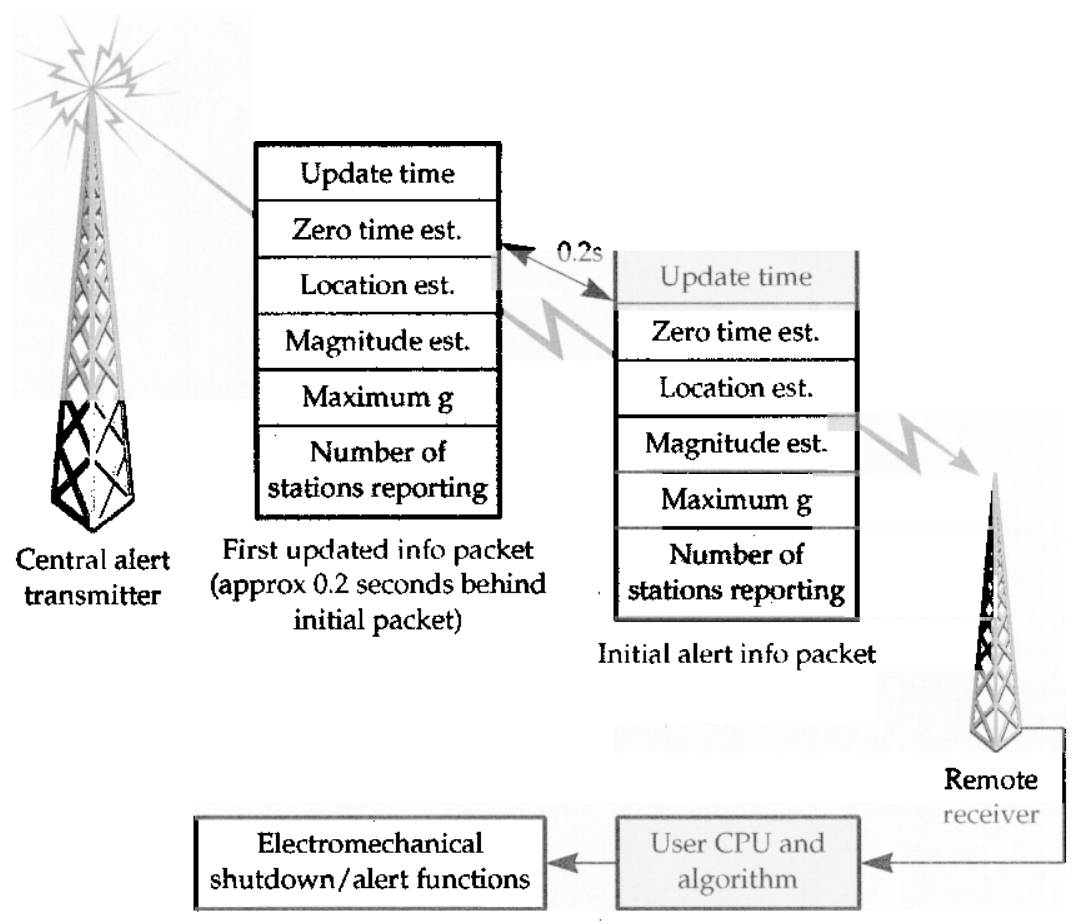

Figure 2. Samples of alert system information packets, which are continually updated by the EAS.

ance for false alarms. For example, one automated response might be to have a fire station door opened by a switch that is controlled by the paging receiver. Such a switch could be activated on receipt of the first alert information packet. Another automated response might be to have a pager-CPU-electromechanical valve system programmed to shut off a gas main. However, before the system initiated this action, the receiver CPU would analyze the incoming earthquake parameter estimates and close the valve only when the location, size, time, and reliability estimates met the defined criteria. This type of action is needed to protect against false alarms because the cost of shutting down a gas main is significant. Numerous other useful receiver systems could be developed by the commercial sector, and there will be profit opportunities in marketing such receiver systems. The various user systems constitute the user receiving and response systems.

In the following section, we describe the specific design of the EAS.

\section{Distributed Strong-Motion Network}

The U.S. Geological Survey maintains an extensive seismic network in California, called CALNET, with more than 100 seismic stations in the greater San Francisco Bay Area 
alone. However, numerous system upgrade and institutional use issues must be overcome before many of these existing stations can be incorporated into an EAS strongmotion network. Consequently, we recommend that a strong-motion network specific to the EAS mission be established. There are several advantages to establishing a network dedicated to the EAS mission:

1. An EAS strong-motion network can be located in relatively high seismic noise environments. Unlike microseismic monitoring sites-which measure very small seismic events and thus must be located in relatively quiet seismic areas, away from cities, roads, and other seismic sources associated with human activities-an EAS network will require that each station monitor the strong motion at levels well above that associated with most human activities. Therefore, station sites can be established at communication hubs and manned facilities, and in general, the EAS can exploit locations where infrastructure and maintenance are maximized.

2. Communication links in a dedicated EAS network can be established with particular attention to the survivability of that link during strong-motion conditions. Many existing microseismic monitoring stations take advantage of whatever lowcost communication link is available with no concern for link survivability during strong ground motion conditions.

3. An EAS network can use reliable, low-cost accelerometers that adequately cover the strong-motion monitoring amplitude bandwidth (about 0.01 to $1.0 \mathrm{~g}$ 's). Limited bandwidth focused on the amplitude band of interest will ease the communication bandwidth requirement, which is particularly important in radio telemetry links. Existing microseismic stations must somehow provide a large communication bandwidth and monitoring amplitude bandwidth to measure and transmit both small and large events.

A fully operational EAS strong-motion network in the Bay Area can be accomplished with about 50 stations distributed more or less uniformly along the major faults in the region [6]. The stations must all communicate data in real-time to a central processing facility.

We have designed a simple, reliable, and inexpensive strong-motion monitoring station that will consist of a three-component Analog Devices ADXL05 accelerometer sensing unit, a vertical component weak motion sensor for system testing purposes, a 16-bit digitizer with multiplexing, and communication output ports for RS232 modem or radio telemetry. The unit will be battery-powered, and the batteries will be trickle charged via conventional ac or solar-panel power.

Fire stations around the Bay Area provide ideal locations for strong-motion monitoring stations. Because there are numerous fire stations in the Bay Area, we can easily determine a subset of 50 stations that would provide adequate geographical coverage of the region (Figure 3). The emergency response and mitigation function of the EAS is consis- 


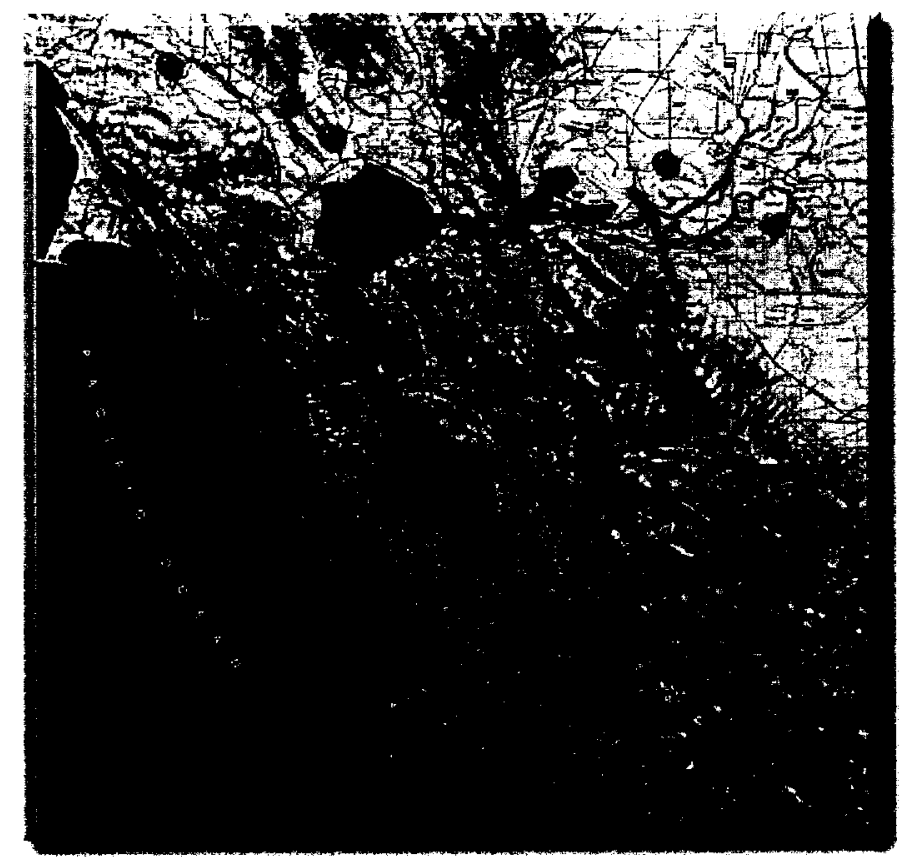

Figure 3. Artist's conception of the distribution of an EAS strong-motion monitoring network in the San Francisco Bay Area. Actual locations will be determined by considering geographical coverage requirements and communication infrastructure.

tent with the emergency function of a firehouse. This dual use of emergency response resources is in general embraced by emergency service professionals. Fire stations are manned 24 hours a day, providing onsite personnel for station debugging should problems be detected at the central station. Also, ac power is readily available, and many fire stations have good communication systems and communication towers that will provide good options on the seismic data communication link. Many of the fire stations that are selected as seismic stations can also be prototype users by installing pager-driven station door openers.

The prototype network will consist of about 12 strong-motion stations, located at participating fire stations, and it will provide as wide a geographical distribution about the Bay Area as allowed by the data communications method we use.

\section{Central Processing Station}

The real-time central processing facility must be recognized, more that any other subsystem of the EAS, as a continually evolving capability. As the prototype system is operated, the data processing algorithms will be continually refined. Consequently, the 
prototype system will be viewed as an initial effort to obtain real-time estimates of earthquake parameters with a minimum of sophistication. To produce prototype central processing facilities, we must develop:

1. Real-time data flow and buffering architecture.

2. Algorithms to estimate earthquake parameters such as location, size, time, and reliability.

3. Earthquake playback capability to test and develop the system.

4. Raw data and data-analysis history archiving features.

5. Algorithms to detect glitches and false alarms.

6. Rigorous system testing via playback scenarios and operational analysis.

Many of the algorithms exist, such as those to determine location, and can be executed rapidly. Some algorithms require an operational system and some operational history before they can be developed (e.g., the algorithms to detect glitches and false alarms). The algorithms that will require the most effort and clearly entail a significant ongoing research component are those that attempt to estimate final earthquake magnitude from early characteristics of the earthquake waveform.

The earthquake rupture travels at the S-wave velocity (about $3.7 \mathrm{~km} / \mathrm{s}$ ), and large earthquakes can rupture $100 \mathrm{~km}$ of fault or more; therefore, the rupture process itself can take 10 seconds or more. These facts beg a key question in estimating magnitude: Do large earthquakes initiate differently than do small to moderate earthquakes? Stated another way: Is there information in the characteristics of the waveform radiated early in the rupture process that forecast the final extent of rupture? The jury is still out on this important question.

Several researchers have tried to estimate magnitude from characteristics of the initial waveform. The Japanese Urgent Earthquake Detection and Alarm System estimates the earthquake magnitude by the dominant period of the initial P-wave arrival [7]. Toksoz [8] has shown that with sensors distributed along specific strike-slip faults, reasonably accurate estimates of fault rupture extent and slip can be made in real time. Using a neural network that is trained on weak and strong-motion data, Leach [9] has demonstrated some success in forecasting final magnitude from the first few seconds of the recorded waveform. Anderson [10] has investigated the waveform characteristics of moderate to large earthquakes in the subduction zone off the Pacific Coast of Mexico and concluded that there are no consistent differences between moderate and large earthquakes in the early waveform for this tectonic region.

The magnitude estimation issue, however, does not negate the utility of an EAS. Even if researchers eventually determine that magnitude cannot be reliably forecast from the initial waveform data in the Bay Area, applications that are tolerant to false alarms may still be chosen to act on the first EAS information packet sent. Furthermore, since the mag- 
nitude estimates are updated as more waveform data is received at the central, they certainly will be more reliable as the earthquake rupture evolves. Most important for an operational EAS is to accurately estimate the reliability of each magnitude estimate, which requires research on magnitude estimation specific to the Bay Area as well as a functioning prototype system with which to test new algorithms.

\section{Warning Communications System}

A prototype warning communication system for the EAS has been established. The complete system consists of a dedicated paging communication system with paging transmitters on Mount Diablo and at Coyote Hills, near the eastern end of the Dumbarton Bridge. The complete system will use simulcast transmission from the two transmitters and will be controlled via microwave relay from LLNL, as shown in Figure 4.

The existing paging communication system employs one paging transmitter at the top of Mount Diablo and is controlled via a microwave relay link from LLNL's Building 271. Paging broadcasts can be received throughout most of the Bay Area; however, there are some shadow zones along the western flank of the East Bay coastal hills (e.g., Hayward, Fremont, Berkeley). The existing system is completely dedicated to the EAS warning transmission; consequently, it has been optimized for minimum delay in the paging broadcast. Timing tests demonstrate that an 80 -character digital string sent from an LLNL computer is received by pagers throughout the Bay Area is less than 2 seconds.

The paging system employs a single transmission frequency that all user response systems must be tuned to. The frequency is licensed to LLNL by the Federal Communications Commission without altitude restrictions and allows for operation at transmission power up to 25 watts. The pager system at Mount Diablo consists of:

- A Motorola Purc 5000 75-watt paging transmitter that is capable of simulcast broadcasting.

- A Zetron paging terminal.

- Microwave receiver dish, rack, and modem.

- Equipment shelter and 60-ft antenna tower.

The length of the character string that summarizes the earthquake location, zero time, magnitude, and reliability has not been fixed but will certainly be less than 80 characters. The protocol and format will be consistent with the CUBE system that sends pages on significant earthquakes within 2 minutes of the event.

\section{User Receiver and Response Systems}

We anticipate that the commercial sector will supply numerous and varied warning receiver systems once an earthquake alert system is considered operational. For the pur- 


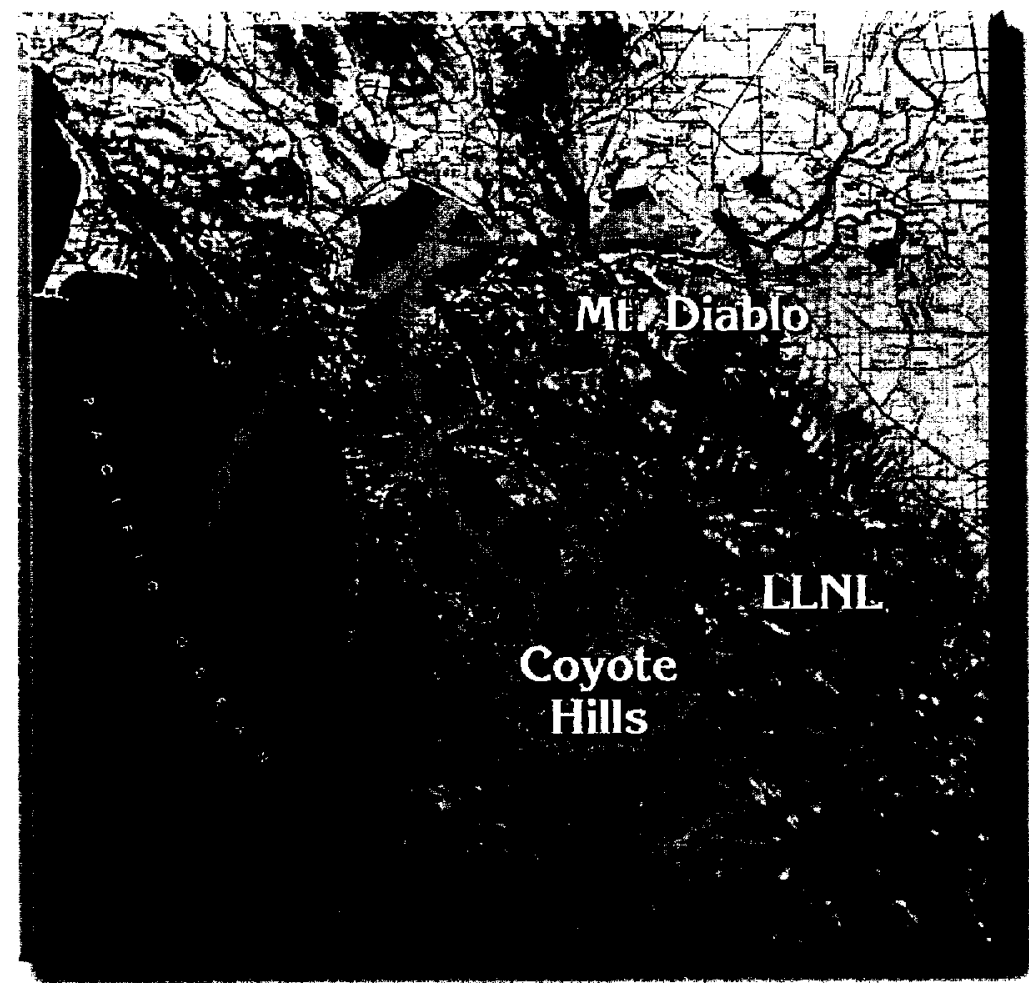

Figure 4. The warning transmission system, which consists of paging transmitters located at Mount Diablo and Coyote Hills. These transmitters will simulcast broadcast the warning information packet that is generated at the LLNL central computer. The packet is transmitted via microwave to Mount Diablo and from there to Coyote Hills.

poses of prototype development and system demonstration, however, useful warning receiver systems must be explored. We focus on two prototype demonstration systems: (1) a pager-driven closure switch for opening fire station doors, and (2) a pager display sign showing an alert message and a display of warning packet information.

The pager-driven closure switch is a simple warning receiver system for false-alarmtolerant facilities-those facilities that prefer to maximize lead time even though this increases the probability of false alarms. Several fire stations have agreed to be part of a prototype demonstration system, using the initial warning signal to open the fire station doors. Forming partnerships with fire stations as initial prototype EAS users will be important in demonstrating the potential applications of the system.

The pager display sign system will consist of large, commercially available signs that will be updated with the newest earthquake parameter estimates as they are issued by the EAS. This system will be for demonstration purposes only. A few systems will be distributed to key facilities to demonstrate system capabilities and promotion. 


\section{Future Plans in Establishing a Fully Operational EAS}

Operational experience with a prototype EAS is a prerequisite to detailed planning for a transition to a fully operational system. Our intent here is to list the upgrades and issues that we believe must be resolved before an operational EAS can be established:

- Upgrade number of strong-motion stations to about 50.

- Establish independent strong-motion network telemetry to a second central processing facility.

- Analyze operational experience with false alarm scenarios.

- Set up paging transmitters for full Bay Area coverage.

- Establish robust real-time earthquake parameter estimation and glitch detection algorithms.

- Analyze EAS performance and survivability for large credible earthquakes.

- Integrate the system with the emergency response community.

- Expand group of system users.

- Plan a media campaign to promote the EAS.

- Conduct a public awareness and education campaign.

- Develop industrial partnerships to develop warning receiver systems.

- Analyze and resolve system liability issues.

\section{References}

[1] Cooper, M. D., Editorial in San Francisco Daily Evening Bulletin, November 3, 1868.

[2] Heaton, T. H., "A Model for a Seismic Computerized Alert Network," Science 228, 987-990, 1985.

[3] Holden, R., R. Lee, and M. Reichle, Technical and Economic Feasibility of an Earthquake Warning System in California, California Division of Mines and Geology, Special Publication 101, 1989.

[4] National Research Council, Real-Time Earthquake Monitoring, National Academy Press, 1991.

[5] Draft Rapid Earthquake Data Integration Project Plan, private communication, University of California at Berkeley, January 1994.

[6] Harben, P. E., Earthquake Alert System Feasibility Study, Lawrence Livermore National Laboratory, Livermore, CA, UCRL-LR-109625, December 1991.

[7] Nakamura, Y., "Earthquake Alarm System for Japanese Railways," Japan. Railway Eng. 28(4), 1989. 
[8] Toksoz, M. N., A. M. Dainty, and J. T. Bullitt, "A Prototype Earthquake Warning System for Strike-Slip Earthquakes," Pure Applied Geophys. 133(3), 1990.

[9] Leach, R. R., and F. U. Dowla, Earthquake Early Warning System Using Real-Time Signal Processing, Lawrence Livermore National Laboratory, Livermore, CA, UCRL-JC123270, 1996.

[10] Anderson, J. G., and Q. Chen, "Beginnings of Earthquakes in the Mexican Subduction Zone on Strong Motion Accelerograms," Bull. Seism. Soc. Am. 85, 1995. 


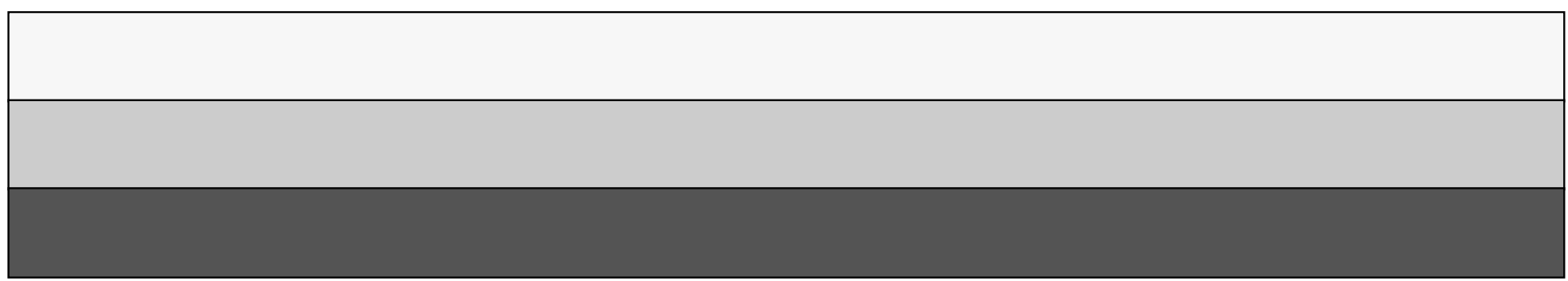

